\title{
Kungfu/wǔshù in the promotion of China's culture and image
}

\section{Introduction}

The promotion of martial arts (kungfu (gōngfu)/wǔshù) is an important element of China's cultural diplomacy. The activity of international organizations and Chinese institutions promoting kungfu/wǔshù contributes to the commercialization of Chinese martial arts in the world. The main objective of this article is to analyze the role of Chinese martial arts in the promotion of Chinese culture and in the process of building the image of the country in the international arena. In the course of my deliberations, I will try to answer the following research questions. Firstly, are Chinese martial arts part of a strategy of promoting China's centuries-old cultural heritage? Secondly, is the Beijing government willing to use them to help build a positive image of China in the eyes of the world's public? In the first part of the article, I move on to definitions of such martial arts as wǔshù and kungfu, as well as the breakthrough moment for the development of Chinese martial arts in the 1950s. The selected period is characterized by the creation of a new sports concept called wǔshù, and the first steps towards local development and standardization being made.

In the second part, cultural diplomacy and its role in the process of creating an international image will be discussed. An important step will be to specify sports diplomacy as a kind of public diplomacy which is becoming increasingly important, especially nowadays when the sport is becoming an important instrument influencing diplomatic relations. However, this is not the only example of the relationship between sport and politics. The internalisation of sport and the internalisation through sport will be briefly outlined as two important processes affecting the country's economy and examples of Asian countries will be given.

The last part of this article will be an analysis of how China presents Chinese martial arts to the world. Should they be treated more as a carrier of centuries-old tradition, or should they be treated as a sports discipline? A look at the activities of the main

\footnotetext{
* Correspondence address: Instytut Bliskiego i Dalekiego Wschodu, ul. Oleandry 2a, 30-063 Kraków, Uniwersytet Jagielloński, Polska, e-mail: e.ciembroniewicz@gmail.com.
} 
organization promoting Chinese martial arts around the world will be the confirmation of these dilemmas.

\section{Chinese martial arts - kungfu/wǔshù}

China's rich culture represents a significant part of the global cultural legacy. China seeks to actively promote the elements of its culture outside, as they have always been attractive export goods and a testimony to the uniqueness of that country. At present, the promotion of Chinese culture focuses on areas such as language, calligraphy, opera, art, dance, and many others. Also, the gōngfu/wǔshù martial arts remain an aspect of China's culture actively promoted abroad opera, art, dance, and many others (Ziętek, 2010: 137).

Most often the Chinese martial arts are referred to as wǔshù (武术) ${ }^{1}$. That term begins with the character $w \check{u}$ (武) ${ }^{2}$, which refers to combat. The second character, shù (术) ${ }^{3}$, indicates that skills related to $w \check{u}$ (武) are meant. The character $w \check{u}$ (武) is made up of two signs: "to stop" zhu $(\text { 止 })^{4}$ and "spear/halberd" ge (戈) $)^{5}$ which means "stopping the spear" (Szymankiewicz, Śniegowski, 1987: 9). The sense of that term is simply "stopping the violence". Another similar term often found in the literature is wǔyi (武艺) ${ }^{6}$. The first character, $w \check{u}$ (武), is shared by both terms and refers to combat, while yi (艺) $)^{7}$ represents sublime abilities expressed as art. In texts from the late Han dynasty period ${ }^{8}$, the term wǔyi was already used to mean a martial art (Henning, 2010: 92-99). Only some English-language and Polish scholars use the term wǔshù to refer to martial techniques and wǔyi to martial arts. Most of the literature does not differentiate between the two and tends to take a simplified approach by using only the term wǔshù. In the $20^{\text {th }}$ century also the term kuoshu (guōshu 国术) ${ }^{9}$ was introduced, meaning a national art. That term was used in Taiwan at the time when wǔshù was forbidden in mainland China.

In Chinese kungfu ( $g \bar{o} n g f u$ 功夫) means attaining a high level of skill in some areas. The term itself is made up of the characters gong (功 $)^{10}$ - achievement, output, and $f u$ (夫) $)^{11}$ - a man. This may be interpreted as the whole of man's achievement and output (Szymankiewicz, Śniegowski, 1987: 9). The most commonly used

${ }^{1}$ wǔshù (武术) - military skill or technique (in former times); all kinds of martial art sports (some claiming spiritual development); self-defense; tradition of choreographed fights from opera and film (recent usage); also called kungfu.

2 wú (武) - military; martial, warlike.

${ }^{3}$ shù (术) - art, skill, special feat; method, technique.

${ }^{4} z h \breve{\imath}$ (止) - stop, detain.

${ }^{5} g \bar{e}$ (戈) - halberd, spear, lance.

${ }^{6}$ wŭyi (武艺) - wŭ - military; martial, warlike; $y \grave{i}$ - art; talent, ability; craft.

7 yi (艺) - art; talent, ability; craft.

8 the Han dynasty (206 BC-220 AD).

9 guó (国) - nation, country, nation-state; shù (术)- art, skill, special feat; method, technique.

10 gōng (功)- achievement, merit, good result.

$11 f \bar{u}, f u ́($ 决- man, male adult, husband. 
term is kungfu (but correct pinyin transcription: gōngfu), referring collectively to all martial arts in China. However, properly it should be used only along with the name of a style e.g. Choy Lee Fut Kung Fu, Chow Gar Kung Fu, Hung Gar Kung $\mathrm{Fu}$, where it simply means being highly skilled in a given style (Osuch, 2002: 12). The term wǔshù was popularized in the second half of the $20^{\text {th }}$ century by the authorities of the People's Republic of China which began using kungfu as a means of bringing up the new generation (New China). The partial rejection of kungfu history, the modification and compilation resulted in the creation of a new style called wǔshù. Although the modern wŭshù with a new structure did not reflect the genuine historical martial arts, it became a sport with a well-developed competition programme, promoted beyond China's borders.

\section{The concept of a new sports discipline and the beginnings of its standardization}

The emergence of the concept of a new sport discipline called wǔshù and the first efforts aimed at local development and standardization date back to the 1950s when they led to the establishment of an institutional framework for organisations promoting Chinese martial arts worldwide. Under the leadership of the Communist party chairman Mao Zedong, the direction of development of modern kungfu was no longer real fight and combat skills but health, exercise, and athletic development. The main goal was to train strong, healthy bodies for national defence and construction of the New China. It was hoped that sport and physical education would play an important role in the restoration of its people (Zhouxiang, 2017: 154). The All China Sports Federation (ACSF), a semistate organisation, was founded in Beijing in 1952 to supervise, organize and promote sport and physical education. Mao Zedong (Chairman of the CCP) wrote an inscription for the All China Sports Federation: "Promote Sport, Build up People's Physique" (Zedong, 1952: 1). In 1955, the Wushu Office was established under the Department of Practice of the Sport Ministry to oversee the development of wǔshù. In 1956, Liu Shaoqi (Vice-Chairman of the CCP) instructed the Sport Ministry to "make efforts to study and reform traditional sport such as wǔshù and qigōng, discover their scientific value and use various measures to promote wǔshü" (Wushu Research Academy of the Sport Ministry, 1997: 364). Consequently, wǔshù was listed by the Sport Ministry as a demonstration event and a seven-day wǔshù show was held in Beijing in 1956. In 1957, the Sports Ministry declared that: "wǔshù is a part of our cultural legacy. We should follow the government and the Party's policies on the national cultural legacy to protect wǔshù and, at the same time, promote wǔshù as a sport" (Fu, 2007: 146). Another very important event was a National Wushu Competition held in Beijing between September 7 and 16, 1958. After this event, the Chinese Wushu Association (CWA) was established (Zhouxiang, 2017: 155). Efforts to establish a unified system of martial arts as a sports discipline 
were commenced by the State Physical Culture and Sports Commission in 1958 (Brzozowski, 2017: 9). At that time, basic exercises were created, which were part of particular sports competitions: tàijíquán, chăngquán, nánquán, nándào, dāoshù, jiànshŭ, qiāngshù and gùnshù in the competition of sports fights săndă and qingdá. Classifications of "hard and soft styles", as well as "internal and external styles", were also implemented, based on schools such as Shaolin, Wudang, Emei, and others (Brzozowski, 2017: 9). Under the patronage of the State Physical Culture and Sports Commission and the Chinese Wushu Association, new ideas concerning the future form of Chinese martial arts and concepts of their development were being extended. Shortly afterwards, sport wǔshù became part of the physical education curriculum in Chinese primary schools. In 1986, thanks to the consent of the Government of the People's Republic of China, the China Wushu Research Institute was established as a place to work on the competitive development of adepts, physiology and technical research on this discipline of wǔshù as the national Chinese sport (Brzozowski, 2017: 10). Its task was to gather a team of teachers, trainers, and referees in this discipline, publish didactic materials, and train coaches from outside China. Attempts were made to recreate the traditional martial arts, e.g. through research conducted to create a wǔshù encyclopaedia - Wǔshù dà cídiăn (武术大辞典) containing the list of all wǔshù techniques known at that time. After 6 years of work, it was possible to recreate and systematize almost 500 different wǔshù styles and schools; nevertheless, the martial arts did not regain their high status from the period preceding the rapid transformations in the $20^{\text {th }}$ century China.

For this article, the following assumptions have also been made. Today, in a broad sense, Chinese martial arts are treated as a carrier of centuries-old tradition (combining Confucian, Buddhist, Taoist and other themes), while in a narrow sense they are treated as a sport discipline called wǔshù. The sportsmanship of Chinese martial arts initiated in the 1950s defined the institutional framework of organisations promoting them all over the world. Efforts are underway to include wǔshù in the Olympic disciplines. The promotion of Chinese martial arts is associated with economic benefits for China. They are an important part of popular culture, while popularization of kungfu/wǔshù is connected with the popularization of tourism in the regions of their nascence (e.g. the Shaolin, Emei, or Wudang monasteries).

\section{Cultural diplomacy and its role in the process of creating an international image}

Individual countries have different cultural potentials, conditioned by their history and traditions. Adequate exposure of cultural values effectively strengthens the position of the state and influences its perception in the world in a positive way. Cultural diplomacy and sports diplomacy, apart from supporting the implementation of specific for- 
eign policy objectives, are tools for creating an international image which is supposed to contribute to the growth of trust towards a given country. In the Lexicon of Political Science, an image (political image) is a shape, image of a political figure of an individual, group, organisation or institution, created in the consciousness of the recipients. It contains evaluative elements influencing decisions and actions taken by other entities. An important informational and creative factor, which is important for image creation, is the mood of public opinion (Antoszewski, Herbut, 1999: 644-645). Therefore, cultural diplomacy should contribute to increasing trust in a given country.

The shaping of China's positive image is becoming one of the key drivers behind China's cultural diplomacy nowadays. The interest both in cultural diplomacy and in the concept of “soft power" (in the Chinese terminology gōnggòng wàijiāo 公共外交, ruăn shíli 软实力) has grown rapidly in the Chinese academic discourse since 2007 as evidenced by compelling research papers. The most in-depth study of the process of building an international image by China was published by Zhou Mingwei. The National Image volume, edited by Zhou is a comprehensive analysis and plan of "building" the Chinese international image, as well as one of the few studies trying to analyze the image of China in the world based on foreign public opinion polls (Zhou, 2008). The paper is also unique because of its critical analysis, which China's international image is lacking in. Ingrid d'Hooghe and Lin Kai also presented interesting works on building China's international image. The publication of Lin Kai touches upon a key aspect of the lack of understanding and misinterpretation of the presented image, especially by Western societies (d'Hooghe, 2011: 19-35; Lin, 2012: 72-79). A similar approach to the subject can be found in Liao Hongbin, Tian Jianmin and Zhou Houhu (Liao, 2007: 111-114; Tian, 2008:126-132; Zhou, 2012: 34-47). Han Fangming, Zhao Qizheng and Ke Yinbin and Liao Hongbin also wrote about public diplomacy as a tool to create a positive image (Han, Zhao, Ke, 2012; Liao 2009: 100-103).

A number of Chinese analysts are of the opinion that public diplomacy is in principle a form of cultural diplomacy because the concept of public diplomacy is not only deeply rooted in culture (Ji, 2012: 327-330), but culture also determines its key objective, helping to limit or even eliminate the hostility that people feel abroad in relation to both the government in Beijing and to the Chinese nation (Wang, Ji, 2012: 13-19).

Although China is seen to be more culturally active abroad, its impact on global cultural trends remains limited. According to surveys, the international image of China is poorly perceived or meets with mixed reactions. In The Soft Power 30. A global ranking of the Soft Power 2018 report, China was ranked only $27^{\text {th }}$ (McClory, 2018). It is worth noting, however, that in the Culture Ranking category, China was ranked 9th after the USA, Great Britain, France, Germany, Spain, the Netherlands, Australia, and Belgium 
(McClory, 2018). However, this does not discourage the Beijing government from making further attempts to improve its image in the world and strengthen its cultural presence.

\section{Sports diplomacy}

The development of new field of public diplomacy, which is sports diplomacy, is also worth noting. The term sports diplomacy is presented by researchers in different ways. According to David Rowe, sports diplomacy is a relatively safe, gentle way of "making friends" and solving conflicts (Rowe, 2011: 115). Jacquie L'Etang presented a similar view, according to which sport is used by governments in public diplomacy to signal a desire to strengthen relations (L'Etang, 2013: 81). Anurag Saxena claimed that sport is used as a political tool to improve (or sometimes make worse) diplomatic relations between two entities (Saxena, 2011). Other researchers, such as Ellis Cashmore and Phillip D'Agati present a similar view (Cashmore, 2000: 349-350; D'Agati, 2013: 13). The promotion of a sport discipline and its successes have already been used by several countries to build their prestige in a broad sense as Baruch Hazan pointed out (Hazan, 1976: 127). However, it is only now that this type of diplomatic activity is gaining more and more attention in the academic community.

An important research paper by Fan Hong and Lu Zhouxiang is The Politicisation of Sport in Modern China. Communists and Champions (Hong, Zhouxiang, 2013). It is the first book in English that examines key issues in sport in the People's Republic of China from 1949 to 2012 in the chronological order in the context of Chinese history, politics, and society. By analyzing the relationships between sport, diplomacy, politics and social transformation in China, the book examines how sport has played an important role in China's rise in the $20^{\text {th }}$ and 21st centuries, and how China embraced the Olympic Movement, as well as influenced the world through the Olympic Games. Sports diplomacy was also described by Zhang Qingmin, Richard Tomlinson along with Orli Bass and Thomas Bassett and Thompson (Zhang, 2013: 211-233; Tomlinson, Bass, Bassett, 2011: 33-48; Thompson, 2008). An interesting approach, which is worth quoting, was taken up by Qing Luo (2010: 1824-1872) with an article entitled "Encoding the Olympics - Visual Hegemony? Discussion and Interpretation on Intercultural Communication in the Beijing Olympic Games" (Qing, 2010: 1824-1872). The article is about the relationship between media and Olympics, the communication complexity of the global mega-event, and the communication strategy of China from the experience of Beijing 2008. An equally important article is "The Representation of the 2008 Beijing Olympic Games: The Rise of China's Soft Power" by Yu-Nu Lu. He focuses on the rise of China's soft power and gives some details on how Chinese authority demonstrated its soft power through the successful hosting of the 2008 Beijing Olympic Games (Lu, 2011:29-40).

The subject of sports diplomacy is almost completely absent in Polish scholarship. Michał Korbiecki's works are among the few studies in which we can find an analysis of 
sports diplomacy, in particular, its examination aimed at analyzing the concept of sports diplomacy concerning the diversity of the forms it covers (2015). Korbiecki attempted to formulate a specific typology of sports diplomacy and to answer the following research question: is sports diplomacy an effective form of a state's external activity, or should it be treated as an optional addition to the classic forms of diplomacy? In his research, he puts particular emphasis on the issues of building the image of the state through sport, and the possibility of establishing diplomatic contacts in situations of antagonistic relations between individual countries. In his works, we find references to the role of sport in Chinese politics and its use to improve the international image, although he does not include kungfu/wǔshù in his deliberations. Maksym Gdański also wrote about the use of culture and sport in Chinese politics. He stresses that the perception of the country by other entities is one of the key issues for their activity in the international arena. $\mathrm{He}$ also described the objectives of China's public diplomacy, pointing out international acceptance of China's political system and policy model; being seen as a stable, trustworthy and responsible economic partner, and now also as a powerful economy that should not be feared at the same time; being seen as a trustworthy and responsible member of the international community, who is able to contribute to the creation of peace in the world; recognisability and respect for the unique culture which dates back to antiquity (Gdański, 2017). In his reflections, he analyzes the causes of difficulties in improving China's image in the international arena, despite intensive public policy actions and the strengthening of China's soft power.

\section{Sport and image}

Sports diplomacy, perceived as an attribute of states, apart from supporting the achievement of specific foreign policy goals may also be oriented towards building a positive international image. This use of sport may take a number of forms, including e.g. athletes' successes, sport contacts and the organization of sport events (so-called megasport events) (Kobierecki, 2015).

Success in sport has traditionally been employed by a number of states for the broadly defined construction of their own prestige (Hazan, 1976: 127). It is even claimed that the ability to promote the national prestige is one of the most unique features of sport. Sport victories have been used for prestigious purposes by such states as the Third Reich, the USA, the Soviet Union or the German Democratic Republic during the Cold War and nowadays for example by China in the context of the Olympic Games in Beijing or by Russia during the Sochi Winter Olympics (Kobierecki, 2015: 116). Governments are keen to support the development of elite sports, financing the construction of facilities or sport programmes, hoping to gain global prestige resulting from their athletes' victories. Building international prestige through sport success may be defined as 
part of public diplomacy although there have been cases of sport being used to build image for propaganda purposes.

The internalization of sport or internalization through sport are two important processes influencing national economy. The internalization of sport is the development of sport organizations through establishing international relations. The entities involved include sport unions, sport leagues, sport clubs, stadium operators and athletes themselves. In turn, the internalization through sport may be understood as the use of sport by government, local government units, enterprises and other organizations for the achievement of their own purposes (Sznajder, 2017: 95).

Sport thus proves to be an important tool useful in the process of economy internalization. International sport events strengthen the brand image of a country, region and city, as well as of the products originating from a given country. The effects of an appropriately developed image include: an increased interests among foreign tourists in visiting the country, a boost in the exports of products manufactured there, and even a rise in foreign investments in the country (Sznajder, 2017: 96).

Since 1960s the governments of Asian states have been noticeably intensifying their internalization efforts. They have been seeking to organize international sport events, from the 1964 Summer Olympics in Tokyo (Japan), the 1988 Summer Olympics in Seoul (South Korea) and the 2008 Summer Olympics in Beijing (China) to the 1972 Winter Olympics in Sapporo and those in 1998 in Nagano, both hosted by Japan. Also smaller sport events should not be ignored as they attract fans, media and sponsors, which is vital from the viewpoint of the promotion of those countries. For example, in 2002 the FIFA Football World Cup was hosted jointly by South Korean and Japan. The ability to host such a prestigious sport event in the two countries testifies to the high level of organization and cooperation between them. Also the IAAF organizes world championships in athletics in Asian countries. In 1991 and 2007, they were hosted by Japan and in 2011 by the Korean city of Daegu. Obviously, large sport events contribute to the promotion not just of the host states, but also of host cities. That contribution covers long-term material effects in the form of developed sport infrastructure i.e. modern stadiums or other sport facilities, but also e.g. transport infrastructure. The actions supporting the internalization of national economy also include campaigns promoting the country abroad, involving the competent state administration units, clubs and other sport organizations (Sznajder, 2017: 17).

\section{China introduces kungfu/wushù to the world}

China, which hosted the Olympic Games in Beijing on the August 8, 2008, focused on the possibility of establishing contact with the audience during the Olympic Games to show the value of its unique culture. The opening ceremony was attended by about 35 million people, and the entire Olympic Games, according to the research, were ob- 
served by 4.7 billion people, i.e. 70\% of the world's population (Gdański, 2017). The organization of this event aimed to present China, its culture and society in a very positive light, which emphasized the attractiveness of this country (Delgado, 2016: 5-7). Wüshù was also able to present itself during the opening ceremony of these games. Thousands of adepts performed an impressive spectacle promoting this sport (beijing2008, 2017). During the 2008 Olympic Games in Beijing, an Olympic Wushu Tournament was organized as part of its Culture and Education Programme, applying the rules and standards of the Games (MacLeod, 2008) ${ }^{12}$. However, it was not the only time when wǔshù marked its presence during the Olympic Games.

Chinese martial arts have a centuries-old tradition always cultivated in the home country. Only the $20^{\text {th }}$ century turned out to be a century of dynamic changes. Kungful wǔshù began to take the form of a sport based on elements of traditional schools and combat styles. A significant event in the history of wǔshù development was the first official show abroad, which took place during the 11th Summer Olympic Games in Berlin in 1936 (Wang, 2012: 106; History of Wushu, 2019). Team of nine traditional masters performed a show containing elements of tàijí and traditional weapon choreographies (1936 Summer Olympics in Berlin) (taichi-kungfu.cz, 2015). The performance met with great approval, to such a degree that the German press described the performance of Chinese competitors as a unique sport discipline, combining health, fitness, and beauty ${ }^{13}$.

\section{Promotion of Chinese martial arts today}

Today, the International Wushu Federation (IWUF), which is the largest international organization in this field, plays an important role in the promotion of this discipline (History of Wushu, 2019). In 1991, it organized the first Wushu World Championships in Beijing. Currently, IWUF is not only popularizing sport wǔshù, but also, since 2004, has intensified activities aimed at revitalizing traditional Chinese martial arts. It is recognized by the International Olympic Committee. It associates 152 countries from 5 continents, forming federations of continental and regional scope. When IWUF was established in 1990 in Beijing, the inclusion of wǔshù in the list of official Olympic disciplines was only beginning to be born as a target for wǔshù practitioners all over the world. During the 30 years of its activity, the wǔshù has made significant progress and has completed many important stages to become an Olympic discipline. In 2002, the IOC official-

12 Andrzej Topczewski, the representative of Poland, found himself among the eight best wǔshù players.

13 At the beginning of the $20^{\text {th }}$ century, numerous events promoting Chinese martial arts were organized. The most important are as follows. In 1923, the Chinese National Wushu Games were held in Shanghai. In 1928, the Nanjing Guoshu Guan was established and the name wǔshù was officially changed to Guoshu (national art) to systemize wǔshù practice, promote and develop it nationwide. Numerous wǔshù meetings and competitions were organized, featuring taolu, as well as contests with weaponry and barehanded combat. In 1929, Wushu Taolu was included in China’s $3^{\text {rd }}$ National Games. In 1936, Chinese wǔshù delegation performed a demonstration at the $11^{\text {th }}$ Olympic Games held in Berlin. 
ly recognized the IWUF during its $113^{\text {th }}$ session held in Salt Lake City (Utah, USA). In 2012, the IWUF made presentations to the Olympic Programme Commission in Lausanne (Switzerland), and in 2013, to the Executive Board of the IOC in St. Petersburg. Wushù was shortlisted for inclusion as an official event in the 2020 Summer Olympic Games. In August 2014, another prestigious event took place - the Nanjing 2014 Youth Wushu Tournament was held as part of the IOC's Culture and Education Programme (IWUF's Path to the Olympics, 2019).

So far, the IWUF has managed to organize prestigious events around the world, such as Wushu World Championships (14 editions), Junior Wushu World Championships (7 editions). Statistics show a steady increase in participation and an increasing level of athletes' skills, manifested in the scale of difficulty of acrobatic elements or the level of training. The Federation has also developed elite sports championships, including the World Cup in Sanda, the World Cup in Taolu and, in the form of the Taijiquan World Championships, has created a tournament dedicated to the world-famous sport of taijiquan (IWUF's Path to the Olympics, 2019) ${ }^{14}$. The ever-growing World Kungfu Championships (WKFC), which promotes sport for all, is gaining increasing popularity and will be held in 2019 in Emeishan, China, for the eighth time. The championships are particularly attractive because they are connected with the promotion of tourist regions associated with the birth of historical martial arts (Shaolin Monastery or Wudang Monastery). The IWUF has gained wide recognition in the global sports community, successfully listing wǔshù as a competitor or show sport in a number of important and diverse multidisciplinary sports competitions such as the Asian Games, the Summer Universiade, the World Martial Arts Games, the Lusophony Games, the African Youth Games, the Oceania and Pacific Master Games and the Islamic Solidarity Games (IWUF's Path to the Olympics, 2019). IWUF aims at promoting wǔshù in both the world sports community and the IOC. The Federation will again apply to be included on the list of Olympic sports in connection with the Summer Olympic Games to be held in Paris in 2024.

As mentioned earlier, the World Kungfu Championships (WKFC), which are organized by IWUF with traditional school practices and combat styles in mind, are becoming increasingly popular. It is also worth noting that World Kungfu Championships are connected with the promotion of tourist regions associated with the birth of historical martial arts. First held in 2004, the WKFC takes place biennially and features thousands of competitors in all age groups competing in a wide variety of events. This event provides an excellent platform for practitioners of all ages and varying skill levels within all traditional kungfu styles to foster understanding through skill and cultural exchanges. In 2004 and 2006, the competition was held in Zhengzhou near the Shaolin monastery, in 2008 and 2010, in Shiyan where the Wudang monastery is located, and in 2017 and

$142^{\text {nd }}$ World Taijiquan Championships took place in Warsaw and were hosted by the Polish Wushu Association. 
2019, in Emeishan which is famous for its Emei monastery. This is an excellent example of the increased interest of foreign tourists in visits to these regions (Competitions, 2019).

Another example of IWUF's efforts to popularize wǔshù as a sport and kungfu as traditional martial arts styles, and at the same time consolidating both communities of practitioners, was the establishment of the international World Wushu-Kungfu Day. The World Wushu-Kungfu Day is a global celebration of Chinese martial arts. It was established on September 28, 2017, at the IWUF Congress in Kazan, Russia, to enable as many people as possible to come together and celebrate this form of activity. IWUF is committed not only to pursuing inclusion of wǔshù in the Olympic Programme, but also to wǔshù becoming part of a globally shared, healthy lifestyle (World wǔshù kungfu day, 2019). A special Twitter profile has been created for this purpose, \#wwkd2019, where affiliated national and regional federations from all over the world promoting kungfu/ wǔshù published posts testifying to their participation in this international campaign.

\section{Conclusions}

In conclusion, it can be said that Chinese martial arts may be part of a strategy to promote China's centuries-old cultural heritage. The Beijing government is keen to use them to help build a positive image of China in the eyes of the world's public. This is evidenced by the development of international organizations and intensified activity of Chinese institutions, whose aim is to popularize Chinese martial arts in the world. The promotion of kungfu/wǔshù develops in two directions: promoting the sport, bringing the possibility of sports rivalry, and promoting culture, emphasizing the transmission of tradition.

Also, a significant change in the image of Chinese martial arts in the popular culture of the second decade of the $21^{\text {st }}$ century is noticeable, creating not only an attractive, but also more comprehensible picture of Chinese martial arts.

\section{Bibliography}

About IWUF (2019), http://www.iwuf.org/about-iwuf/ [access: 25.05.2019].

Antoszewski A., Herbut R. (1999), Leksykon politologii, Warszawa.

beijing2008, (2017, June 22), Beijing 2008 Opening Ceremony Highlights [Video file fragment 38:40-42:52], https://www.youtube.com/watch?v=Me9PGswBavw [access on: 5.04.2019].

Brzozowski K. (2017), Polski Związek Wushu. Regulamin rozgrywania konkurencji form tradycyjnych z komentarzem, Gdańsk.

Cashmore E. (2000), Sports Culture. An A-Z Guide, London.

Competitions (2019), http://www.iwuf.org/competitions/iwuf-official-events/world-kungfu-championships/ [access: 29.05.2019].

D'Agati, P.A. (2013), The Cold War and the 1984 Olympic Games. A Soviet-American Surogate War, New York.

Delgado D.R.L. (2016), Opening Ceremonies of International Sports Events: The Other Face of Chinese Soft Power, "The International Journal of the History of Sport", No. 33(5), pp. 607-627, https://doi.org/10.1080/09523367.2016.1159200 [access on: 29.05.2019]. 
D’Hooghe I. (2011), The Expansion of China's Public Diplomacy System, [in:] Soft Power in China: Public Diplomacy through Communication, edit. W. Jian, New York.

Fu Y. (2007), The history of sport in China, 1949-1979, Vol. 5, Beijing.

Gdański M. (2017), Zmiana postrzegania wizerunku państwa na postawie soft power Chin, http:// www.polska-azja.pl/m-gdanski-zmiana-postrzegania-wizerunku-panstwa-na-postawie-softpower-chin/ [access on: 29.05.2019].

Han F., Zhao K., Ke Y. (2012), Gonggong waijiao gailun, di er ban [Introduction to Public Diplomacy $2^{\text {nd }}$ edition], Beijing.

Hazan B.(1976), Soviet Propaganda. A case study of the Middle East conflict, Jerusalem.

Henning S.E. (2010), China: Martial Arts, [in:]: Martial Arts of the World: An Encyclopedia of History and Innovation, Vol. 2, edit. T.A. Green, J.R. Svinth, Santa Barbara.

History of Wushu (2019), http://www.iwuf.org/history-of-wushu/ [access: 25.05.2019].

Hong F., Zhouxiang L. (2013), The Politicisation of Sport in Modern China. Communists and Champions, London.

IWUF's Path to the Olympics (2019), http://www.iwuf.org/competitions/other-iwuf-events/ [access: 20.05.2019].

Ji L. (2012), Chuantong wenhua yu zhongguo gonggong waijiao [Traditional culture and Chinese public diplomacy], "Wuhan Kejidaxue Xuebao (Shehui kexueban) ”, No. 14(3).

Kobierecki M. (2015), Dyplomacja sportowa. Sport jako arena prowadzenia dyplomacji międzynarodowej, "Kultura i Polityka", No. 17, pp. 109-122.

Liao H. (2007), Woguo gonggong waijiao de fazhan xianzhuang ji duici fenxi [Analysis of the development status of China's public diplomacy and countermeasure], "Sichuan Daxue Xuebao (Zhexue Shehui kexue ban)", No. 152(5).

Liao H. (2009), Gonggong waijiao: guoji jingyan yu qishi [Public Diplomacy: international experiences], "Dangdai Shijie yu Shehui Zhuyi", No. 1.

Lin K. (2012), Gonggong waijiao zai zhongguo heping jueqizhong de gongneng fenxi [A functional analysis of public diplomacy within China's peaceful rise], "Guoji Guancha”, No. 2.

L'Etang, J. (2013), Sports Public Relations, Los Angeles.

Lu Y-N. (2011), The Representation of the 2008 Beijing Olympic Games: The Rise of China's Soft Power, [in:] China's Quiet Rise. Peace Through Integration, edit. B. Guo, Teng C-C., Lanham.

McClory J. (2018), The Soft Power 30. A global ranking of Soft Power 2018, https://softpower30. com/wp-content/uploads/2018/07/The-Soft-Power-30-Report-2018.pdf [access on: 5.05.2019].

MacLeod C. (2008), Kung-fu makes Olympic showcase debut, "USA Today", 21.08.2008, http:// usatoday30.usatoday.com/sports/olympics/beijing/fight/2008-08-21-wushu_N.htm [access on: 5.04.2019].

mdbg.net, https://www.mdbg.net/chinese/dictionary [access on: 15.04.2019].

Osuch P. (2002), Hung Gar Kuen. Wiecznie żywa legenda, Warszawa.

Rowe D. (2011), Global Media Sport. Flows, Forms and Futures, London.

Saxena A. (2011), The Sociology of Sport and Physical Education, New Delhi.

Sznajder A. (2017), Sport jako biznes w czasach globalizacji, Warszawa.

Szymankiewicz J., Śniegowski J. (1987), Kung fu, wu shu: chińska sztuka walki, Szczecin.

Qing L. (2010), Encoding the Olympics - Visual Hegemony? Discussion and Interpretation on Intercultural Communication in the Beijing Olympic Games, "The International Journal of the History of Sport”, No. 27(9-10), pp. 1824-1872, https://doi.org/10.1080/09523367.2010.481 136 [access on: 29.05.2019].

taichi-kungfu.cz, (2015, January 28), 1936 Summer Olympics in Berlin - Closing Ceremony Kung Fu Demo [Video file], https://www.youtube.com/watch?v=t5F2oKWZPEU [access on: 25.05.2019]. 
Tian J. (2008), 21shiji Zhongguo gongzhong waijiao chutan [Preliminary exploration of China's public diplomacy in the $21^{\text {st }}$ century], "Qianyan", No. 12.

Tomlinson R., Bass O., Bassett T. (2011), Before and after the vuvuzela: identity, image and mega-events in South Africa, China and Brazil, "South African Geographical Journal", No. 93(1), pp. 38-48, https://doi.org/10.1080/03736245.2011.570005 [access on: 29.05.2019].

Thompson D. (2008), Beijing Olympics: More at Stake than Gold Medals, "China Business Review", January-February 2008, http://www.chinabusinessreview.com/ [access on: 15.10.2012].

Wang H., Ji L. (2012), Lun zhongguo tese gonggong waijiao: jiqi lilunde wenhua neihan [About public diplomacy with Chinese characteristics and the cultural connotation of its theory], "Zhongguo yu Shijie", No. 7.

Wang G. (2012), Chinese Kung Fu, Cambridge.

World wushu kungfu day (2019), http://www.iwuf.org/event/world-wushu-kungfu-day/ [access: 10.09.2019].

Wushu Research Academy of the Sport Ministry (1997), Zhonggguo wuhu shi [The history of Chinese martial arts], Beijing.

Zedong M. (1952), Fazhan tiyu yundong, zengqiang renmin tizhi, "Xin tiyu”, No. 7(1).

Zhang Q. (2013), Sports Diplomacy: The Chinese Experience and Perspective, "The Hague Journal of Diplomacy”, No. 8, pp. 211-233, DOI: 10.1163/1871191X-12341257.

Zhou H. (2012), Gonggong waijiao yu Zhong Mei ruanshili zhanlüe [Public Diplomacy and China/U.S. Soft-power Strategies], "Global Review”, No. 1.

Zhou M. (2008), Guojia Xingxiang Zhuanbo Yanjiu Luncong, Beijing.

Zhouxiang L. (2017), Politics and Identity in Chinese Martial Arts, New York.

Ziętek A.W. (2010), Soft Power Chińskiej Republiki Ludowej. "Soft Power z chińska specyfika", TEKA Komisji Politologii i Stosunków Międzynarodowych Oddział PAN w Lublinie, No. 5, pp. 131-147.

Abstract: Sport is a specific form of human activity, contingent on the political and socio-cultural history of a given region/state, strengthening national identity and sense of the distinctiveness of entities living in that region or state. At the same time, it has an unquestionable influence on the process of building and strengthening the country's image in the international arena.

Chinese martial arts are treated not only as a sport called wǔshù, but also as a carrier of centuries-old Chinese tradition. This cultural aspect of kungfu/wǔshù means that the promotion of these martial arts should be considered not only from the perspective of sports diplomacy, but also from a broader perspective, based on the analysis of cultural diplomatic activity in China.

Keywords: Chinese martial arts, kungfu/wǔshù, cultural diplomacy, sports diplomacy, public diplomacy, international image

Article submitted: 27.06.2019; article accepted: 29.09.2019. 